\author{
Ana Paula Carvalho \\ Marlusa Sevilha Gosling \\ António Sérgio Araújo Almeida \\ Artigo recebido em: 17/04/2018 \\ Artigo aprovado em: 25/11/2018
}




\title{
Influências de séries televisivas na afirmação de Destinos Turísticos - o caso \\ da série Borgen
}

\author{
Influences of television series on notoriety of tourism \\ destinations - the case of the Borgen series \\ Ana Paula Carvalho* \\ Marlusa Sevilha Gosling** \\ António Sérgio Araújo Almeida****
}

\begin{abstract}
Resumo: A compreensão da relação entre a produção cinematográfica e a afirmação dos locais de filmagem como Destinos Turísticos Alternativos foi o principal objetivo do presente trabalho. Por meio do estudo de caso da série televisiva BORGEN, pretende-se compreender as relações que se estabelecem nos locais de filmagem e que critérios estão na base da escolha dos mesmos pelos produtores audiovisuais, constatando-se que as séries televisivas influenciam a escolha de destinos turísticos.
\end{abstract}

Palavras-chave: Séries televisivas. Impactos locais. Turismo alternativo. Experiência turística.

Abstract: The main objective of this paper is to understand

\footnotetext{
* Mestranda em Turismo e Ambiente na Escola Superior de Turismo e Tecnologia do Mar (ESTM) do Instituto Politécnico de Leiria (IPLeiria).

** Doutora em Administração e pós-doutoramento em Gestão do Turismo. Professora Associada no Centro de Pós-Graduação e Pesquisas em Administração - CEPEAD/UFMG.

*** Doutor em Ciências do Turismo. Professor Adjunto na Escola Superior de Turismo e Tecnologia do Mar(ESTM) do Instituto Politécnico de Leiria (IPLeiria). Membro Integrado no CiTUR, Centro de Investigação, Desenvolvimento e Inovação em Turismo. Coordenador do Mestrado em Turismo e Ambiente e subdiretor da ESTM/IPLeiria.
} 
the relation between film production and the notoriety of the filming locations as Alternative Tourism Destinations. Through the case study of the TV series BORGEN, it is intended to understand the relations established in the filming locations and which are the criteria basis for their selection by the audiovisual producers, noting that the TV series influence the choice of touristic destinations.

Keywords: Television series. Local impacts. Alternative tourism. Tourism experience.

\section{Introdução}

O presente trabalho aborda a produção audiovisual de séries televisivas e a influência destas para a visita aos locais de filmagem enquanto destinos turísticos. A construção de novos destinos turísticos, bem como os novos recursos associados à produção audiovisual, são questões relevantes para a atual abordagem ao perfil do turista e às suas motivações de viagens. Obviamente, tais informações ajudam a sustentar os agentes dedicados à produção e gestão de experiências turísticas inovadoras e diferenciadoras. A escolha da série televisiva BORGEN (que em 2015 passou na RTP2 em Portugal) para caso de estudo deve-se a vários fatores, entre os quais a especificidade do argumento, as personagens, a origem geográfica da série e sobretudo pelo pertencimento a um segmento de mercado muito específico. A série perpassou a crítica de atores com influência na sociedade portuguesa, incluindo economistas, jornalistas e políticos. Para a realização dos objetivos, buscou-se entender o que está na origem das escolhas dos locais de filmagem e qual o seu poder de sedução. Serão os conteúdos das séries fatores 
definidores do perfil turístico dos locais em questão, e, pelo mesmo modo, da experiência? Por outro lado, em que medida os locais de filmagem podem condicionar a assunção identitária local?

Além disso e como todos os telespetadores e cinéfilos podem apreciar, as marcas continuam a ser utilizadas em cenários como autopromoção dissimulada, em troca de apoio financeiro que essas empresas prestam às produções. Entende-se por isso que uma das pertinências do estudo, além do papel indutor da imagem na produção de séries televisivas para a motivação de visita aos locais de filmagem, terá interesse em compreender as causas e as consequências do poder da imagem num mercado já consolidado pelas redes sociais. O objetivo geral do estudo reside, como já referido, no enfoque dos critérios de seleção para a escolha dos locais de filmagem e se os géneros cinematográficos "rotulam" os destinos e consequentemente a tipologia de turistas.

Surgem assim duas perguntas iniciais de pesquisa, a saber (i) como podem os locais de filmagem induzir a motivação para a visita? E (ii) tomando-se os géneros cinematográficos diferenciadores de públicos, é possível que a produção audiovisual induza ao interesse por novos destinos?

A coleta da informação fez-se em três momentos distintos. Num primeiro momento, foi feita uma revisão da literatura com recurso a fontes secundárias e estudos realizados, para destacar as principais reflexões. No segundo, foram realizadas entrevistas a produtores audiovisuais, responsáveis por film comissions, com a intenção de compreender os critérios de escolha dos locais de filmagem e a sua contribuição para destino turístico. $\mathrm{O}$ instrumento utilizado na coleta da informação foi a entrevista semiestruturada, 
sob o método de Delphi, que permite obter opiniões de especialistas sobre determinada matéria.

O trabalho encontra-se estruturado em quatro seções. No primeiro, a introdução do tema e dos objetivos, o enquadramento teórico dos assuntos abordados e as referências gerais aos pressupostos definidos; no segundo, a metodologia aplicada e os instrumentos utilizados, bem como as considerações sobre a fiabilidade e validade dos mesmos; no terceiro, são apresentados os resultados das respostas obtidas nas entrevistas e a sua validade para o assunto abordado e descrevem-se também os resultados e a informação da análise às respostas dos entrevistados; no quarto, é feita uma reflexão sobre os resultados e considerações do interesse da investigação, as limitações do estudo e equacionadas propostas futuras.

\section{Revisão Bibliográfica \\ Relação entre Produção Audiovisual e Turismo}

Os destinos já reconhecem o poder de atração das produções audiovisuais enquanto ferramenta de promoção para atingir grandes públicos. Por isso, várias organizações responsáveis pelos destinos turísticos investem fundos para captar produções (LARA, 2013). No mundo globalizado de hoje, o comportamento do consumidor é afetado por muitos fatores e novas motivações baseadas na procura de novas experiências (OLIVEIRA, 2008). Segundo Nielsen (2002), o turismo deve considerar todas as decisões e ações do comportamento do turista, de forma a ligar todos os aspetos a questões mercadológicas e que são modeladas pela procura de novas experiências. Para Young \& Young (2008), existe uma relação entre 
o consumo de cinema e de séries e o aumento da procura turística de destinos induzidos nos filmes. Para Hudson e Ritchie (2006), o turismo cinematográfico é um fenómeno crescente em todo o mundo que se alimenta mutuamente, promovido pela lógica da indústria do entretenimento e pelo aumento das viagens internacionais. Em Busby e Klug (2001), o turismo está relacionado com os lugares descritos nos livros e exibido no cinema ou na televisão. São vários os estudos que demonstram que tanto o cinema como a TV criam motivações para viajar. Nos resultados de Cohen (1986), existem filmes altamente poderosos na publicidade dos locais.

Há já exemplos concretos onde esta influência está comprovada. De acordo com Li et al. (2017, p. 183), “o filme Hobbit têve um impacto positivo significativo sobre a economia da Nova Zelândia o, que pode ser atribuído a fatores diferentes. A boa execução das estratégias promocionais durante e depois do filme pode aumentar o efeito que é conhecido na literatura."

Para os profissionais de turismo, deve ter-se em conta todos os aspetos relacionados com a produção de filmes, séries em televisão ou cinema. A audiência dispersa-se e deixa de fazer sentido a plataforma de visualização. Os enredos, argumento e história, os conteúdos ou as imagens dos locais, todos se relacionam entre si e são fatores diferenciadores para as escolhas turísticas. Por meio da análise crítica a reações públicas à série BORGEN, um pouco por todo o mundo, abordar-se-ão quais são os fatores diferenciadores que motivam e influenciam a visita ao local de filmagem, tendo em conta o género da série e a sua relação com o perfil de audiência.

A mudança do paradigma turístico a que se assiste nos últimos anos traduz-se na mutação do turismo de massas que vem 
conduzindo a um turismo segmentado e mais sofisticado, originando novos turistas. Para Nunes (2016), há um novo turista que procura novos lugares. Com os avanços tecnológicos, as preferências alteram-se para formas de entretenimento diversificado em que as possibilidades aumentam significativamente com o livre acesso a cada vez mais informação, o que torna este novo turista mais exigente. O novo turista é assim, aquele que procura novos lugares, experiências criativas, diferenciação, férias ativas e a busca da qualidade dos recursos e serviços turísticos (NUNES, 2016). O novo turista, segundo Poon (1993), citado por Nunes (2016), é caraterizado pela flexibilidade, pela procura de experiências únicas e autênticas e pela afirmação de individualismo, deixando de seguir as massas.

De acordo com Almeida (2012, p. 102) "Nesta comunidade turística que presume um esforço de planeamento estratégico, visitantes, turistas e comunidades autóctones, interagem numa perspetiva de convergência maximizada de vantagens mútuas, fazendo assim sentido falar de sustentabilidade turística."

O novo turista valoriza a cultura, é seletivo, mais experiente, dispõe de inúmeras plataformas tecnológicas, pelo que, a indústria do turismo tem de encontrar novas formas e meios para superar e atender as novas necessidades das expetativas destes novos turistas. De acordo com Duque (2013, p. 19), citado em Nunes (2016), os destinos turísticos têm de se manter competitivos "a par das inovações e procurar manter atualizados, em conformidade com os gostos e necessidades dos turistas", para que assim correspondam às expetativas dos novos mercados. Se a relação entre a produção audiovisual e o território, capta o interesse e as sensações associadas aos argumentos e às personagens que contribuem para o envolvimento 
emocional com as séries, para Kim e Assaker (2014), o turismo audiovisual pode alimentar-se de mais séries diferenciadoras, promotoras de charme. Estas séries nutrem a imaginação e ao mesmo tempo criam diferenciação nas escolhas perante outras produções de séries, como é o caso das telenovelas brasileiras.

\section{O Tangível e Intangível do Não-Lugar dos Locais de Filmagem}

Partindo do pressuposto de que a indústria do audiovisual e o turismo têm pontos evidentes de sinergia e que se podem relacionar entre si na concretização da atividade turística, a qual vem ganhando notoriedade nos últimos anos, considera-se relevante a pesquisa sobre este tema, pois o contexto engloba destinos que emprestam as suas identidades a formas de turismo apelativo, na construção efémera de identidades de não-lugar. Se um lugar se pode definir como identitário, relacional e histórico, um espaço que não se pode definir nem como identitário, nem como relacional, nem como histórico definirá um não-lugar. $\mathrm{Na}$ linha de pensamento de Augé, (1994, p. 167), “o não lugar é o espaço dos outros sem a presença dos outros, o espaço constituído em espetáculo."

Para este trabalho, a ideia do turismo de séries, enquanto fator tangível, aparece como um segmento de turismo ainda pouco explorado, estudado ou divulgado. A abordagem do tema tornase pertinente na medida em que a pesquisa é validada a partir da produção televisiva de lugares fabricados para serem consumidos pelo turista, onde se atribuem valores incorporados, designadamente, como fetiches. É assim que a televisão se destaca na comunicação 
tornando-se simultaneamente um potencial promotor turístico. Por outro lado, a produção audiovisual, indiretamente e de forma intangível é proveniente da exportação de cenários e valores culturais e históricos das produções, um pouco por todo o mundo, através do cinema, televisão, computadores e redes sociais e novos mídia, que tendem a atrair turistas aos locais de filmagem dos países expostos em curto, médio e longo prazo (MACIEL, 2015). Os comportamentos são definidos perante atributos inexistentes, fantasiosos aos olhos do turista, sob as imagens projetadas na série televisiva. Esta série é tão mais motivada para a imagem do destino quanto maior for o envolvimento com o argumento, drama ou personagens (KIM; ASSEKER, 2014).

Assim, o espaço do não-lugar não cria uma identidade na relação com a verossimilhança do imaginário turístico, mas, numa proporção de espaço e história (argumento) transformando-a num local de experiências intangíveis. Conhecer as motivações associadas aos locais de filmagem e à construção de identidades do não-lugar na experiência turística, vai de encontro à atual realidade do crescimento (in)sustentável do turismo em determinados destinos e ao papel que a produção de séries televisivas pode ter na descentralização induzida por interesses e motivações associados aos locais de filmagem. Sendo a televisão um significativo meio de comunicação de massas em todo o mundo, independentemente da diversidade cultural, social ou económica, as séries televisivas são passíveis de ser interpretadas como corresponsáveis pelo comportamento de milhões de pessoas, promovendo hábitos de consumo e induzindo novos destinos.

De acordo com Fu, Ye e Xiang, (2016) o envolvimento 
do público é positivamente relacionado com futuras intenções comportamentais. Tanto a imagem cognitiva como a afetiva mediam a relação entre o envolvimento do público e intenções comportamentais. Sustentam os autores que os resultados ajudam a desembaraçar as relações estruturais entre o envolvimento do público, imagem cognitiva, afetiva e intenção comportamental, o que irá fornecer aos comerciantes de destino informações valiosas para o desenvolvimento de estratégias comerciais.

A televisão tem vindo também a acentuar uma ligação emocional a realidades desconhecidas e a par com as grandes alterações tecnológicas foi-se consolidando na vida quotidiana das famílias. Reconhecemos a sua importância na construção de identidades, na educação, na formação de opiniões, nas tendências, no papel conciliador e humanizador, bem como o seu contrário.

No entendimento de Fu, Ye e Xiang (2016), em particular, o público, pode identificar-se com os personagens e tornar-se empático, ou imergir-se totalmente na história e ignorar temporariamente sua realidade circundante. Estes esforços cognitivos e emocionais são muito suscetíveis de contribuir para a perceção reforçada, conhecimento e sentimentos, dos destinos onde o show é definido (ou seja, imagem de destino). Sublinham os autores que numa perspetiva de marketing, a pesquisa sobre filmes de Turismo analisou como filmes ou programas de TV podem formar e mudar as perceções dos espetadores dos destinos. 


\section{A Autenticidade nos Destinos de Filme}

A autenticidade é um termo ambíguo e de muitos significados. A segmentação do turismo e a diferenciação da experiência conduz ao estudo do comportamento humano no âmbito das emoções e perceções. Segundo Wang (1999), existem três tipologias de autenticidade, com noções relacionadas com o objeto da experiência e as emoções causadas nas relações interpessoais e intrapessoais. O turista procura viver no destino várias experiências explicadas pela sua perceção da realidade, pelos seus valores, status social, educação, modus vivendi, idade e género. Independentemente de qualquer que seja a sua condição, vive uma autenticidade existencial, na medida em que é sentido enquanto tal. A relação entre o turismo audiovisual e a autenticidade existencial é ténue uma vez que o turista espetador já foi induzido pela imagem, pelo argumento, pela história ou pelas personagens que o incorporaram numa série de elementos que no destino se apresentam autênticos. $\mathrm{Na}$ análise do comportamento no destino e das motivações aos locais de filmagem, Riley e Doren (1998), referem que os filmes fornecem objetos e assuntos que induzem a viajar para os locais onde foram filmados. É o caso de estudo de Busby e Klug (2001), que através do inquérito aos visitantes de Notting Hill em Londres, (cenário do filme com Hugh Grant e Julia Roberts), mostra um perfil de visitante bastante conhecedor com a imagem do destino antes da visita. Mostra ainda a particularidade de se identificar em termos visuais com os atores e pertence à mesma faixa etária.

No entanto, existindo uma competição feroz entre destinos, 
as escolhas da produção, os locais de filmagem, a valorização da imagem e a sua representatividade podem comprometer a sustentabilidade dos recursos locais. É o caso de Notting Hill que depois do filme, os seus residentes apresentaram todo o tipo de queixas, nomeadamente a invasão de privacidade. Para Maccannell (1976), o turismo permite resgatar a autenticidade algures noutro local, noutra cultura, ou noutro período histórico. O turista moderno está empenhado na busca de autenticidade, precisamente, porque esta se tornou um bem escasso nas sociedades modernas. De acordo com Maccannell (1976, p. 3) "Por outras palavras, a preocupação da modernidade para a "naturalidade ", nostalgia e busca da autenticidade não são meramente casuais e prendemse a um pensamento nostálgico, anexo às lembranças de culturas destruídas e épocas passadas."

Na série BORGEN, não se conseguindo explicar o seu êxito e paradoxalmente os níveis de share baixíssimos, esta dificuldade é muito evidente. Neste estudo, não se pretende transformar este assunto em problema. Contudo, induz-nos na investigação sobre o modo de como os episódios possam ter sido vistos, e, por conseguinte, ao perfil da sua audiência. Por outro lado, há que referir que as visitas aos locais de filmagem da série não foram nem são de grande afluência, o que pode ficar a dever-se ao tipo de série, trama político, mídia, passado num país do Norte da Europa, Dinamarca, com um nível de vida acima da média dos restantes países. Veja-se por exemplo, o caso do filme do Senhor dos Anéis filmado na Nova Zelândia que registou apenas 5\% de visitantes espetadores aos locais de produção, o que ficará a dever-se à distância a que se encontra do principal eixo de audiência, a Europa. Em contrapartida, a cidade 
de Dubrovnick na Croácia, depois da série Game of Thrones, é um dos destinos mais procurados, travando uma batalha para controlar a visita à cidade ficcional de King's Land onde a série foi rodada. $\mathrm{Na}$ Nova Zelândia, a produção do Senhor dos Anéis promoveu uma logística socioeconómica ligada ao filme, mais de dois anos de produção, quase três mil empregos diretos e indiretos, além da plantação de muitos hectares de plantas. O exemplo do impacto do filme na Nova Zelândia pode representar uma medida sustentável no desenvolvimento turístico.

\section{A Radicalização Psicográfica do Turista Audiovisual}

Ao se entender a oferta turística como objeto transicional, o turista procura na viagem a satisfação da experimentação de lugares diferentes do seu quotidiano e que de algum modo a memória o retenha no lugar visitado. A viagem, em si, transporta-o num ritual que interioriza a experiência turística da mesma forma que a criança ultrapassa a realidade (WINNICOTT, 1971). Se um género fílmico é capaz de induzir o turista aos mais diversos locais, transportando o seu imaginário a uma fonte inesgotável de recursos, pode pensarse que este turista é capaz de uma infinidade de práticas induzidas no género fílmico.

De acordo com Plog (1979), a tipologia de turistas tem por base uma análise psicográfica na perspetiva de explicar o ciclo de desenvolvimento de um destino turístico. Esta segmentação é definida tendo por base valores e estilos de vida. Em geral, considera-se que as principais motivações relacionadas com o turismo cinematográfico são a identificação dos lugares retratados 
na produção, paisagens, a identificação com as personagens, a identificação com os conteúdos (género, tema, história, argumento), (HAYATA; MADRIL, 2009).

A relação do espetador com a produção de cinema ou televisão permite o desenvolvimento de sentimentos, emoções e atitudes em relação aos lugares representados, (KIM et al., 2008).

De acordo com estes autores:

Na sociedade de hoje, a televisão (TV) desempenha um papel central na transmissão da cultura popular para todos os cantos do mundo. Informações sobre notícias, esportes, jogos, filmes, hobbies, viagens e muitos outros tópicos são transmitidos diariamente na TV. Notáveis estórias são fornecidas por séries de drama ou filmes que alimentam donas de casa, trabalhadores, ou membros da família com fofocas ou bate-papo (KIM et al., 2008, p. 164)

Entre a margem da fantasia e da descoberta, os lugares emprestam emoções aos turistas e nesse momento, esta relação, é autêntica para quem a vive ou visita. Há muito em comum entre os turistas de séries ou cinema e os restantes, sendo que, o que os distingue não é o imaginário da viagem mas um imaginário quotidiano mental que quer experimentar reflexos do seu status quo. A oferta turística dos locais de filmagem, do ponto de vista geográfico, enquanto objeto transicional na linha de Winnicott (1971), apresenta-se numa perspetiva intrapessoal. São evidentes as interferências da viagem ao local, a permanência e usufruto nos lugares retratados, a autenticidade construída, com base em fatores intensificadores da experiência. No caso da série BORGEN, estas questões estão associadas ao sistema de valores, às relações de 
género ou à ligação mídia-politica.

A alquimia que joga com as emoções em dimensões de inquietude saudável, fá-los mudar para um mundo onde as suas relações de vida solitária se entrecruzam, como que, por magia, com o espaço. Estar ali onde tudo aconteceu, emerge na intensidade do lugar. No estudo efetuado por Kim e Asseker (2014) sobre as perspetivas de envolvimento comportamental com uma série televisiva coreana, os visitantes do parque temático onde a série é filmada, evidenciam o fato do envolvimento ser maior quanto maior for a sua identificação com a série. Sendo cada vez maior a oferta de destinos turísticos, é importante considerar a competitividade entre eles, fato extremamente importante para a manutenção nas escolhas dos locais de filmagem que marcam assim a sua posição no mercado turístico (DIMOSKA; TRIMCEV, 2012).

Por outro lado, existem parques temáticos na produção de séries televisivas com visitas programadas em momentos de filmagem onde os visitantes são convidados a assistir às filmagens, participando nelas, atingindo níveis de satisfação e de envolvimento emocional que explicam a intimidade e a memória com a série e as personagens (KIM; ASSEKER, 2014). Estes locais identificados como não-lugar, servem o parque temático, sem valores de tradição, tipicidade, líquidos, sintéticos, onde o turista desenvolve simulacros do real, sem o receio do desencanto. O genuíno do verdadeiro produz apenas showcase, exibição e paródia.

Para compreender as motivações associadas à visita a um determinado destino turístico, induzido, ou não, por séries televisivas, filmes, cinema ou qualquer outro recurso, terá de conhecer-se o perfil psicográfico, os valores pessoais, os estilos 
de vida ou as necessidades dos indivíduos que procuram a satisfação nestas viagens. Segundo Nunes (2016) e com base na teoria de Dann (1977), estão identificadas diferenças entre turistas anómicos e em contextos de autodesenvolvimento. Neste modelo, o autor sugere que os turistas são motivados tendo em conta vários elementos, designadamente, a viagem em si, a atração do destino, fatores motivacionais diversos, como a fantasia do destino ou a experiência turística e os seus significados. Para Nunes (2016), a decisão do turista assenta em fatores económicos, relevantes, tais como, o rendimento mensal ou a disponibilidade do tempo de lazer.

Ainda de acordo com Nunes (2016, p. 21):

[...] os fatores motivacionais são divididos em pessoais e interpessoais, em que a busca pessoal é caraterizada pela busca de descanso, relaxamento e prestígio e a busca interpessoal diz respeito à interação social com grupos de viagem. Por outro lado, a evasão do ambiente pessoal que se carateriza com os problemas pessoais, dificuldade e fracassos e a evasão do ambiente interpessoal que se relaciona com os colegas de trabalho, família e vizinhos.

Estas diferenças determinam o perfil de audiência, e podem contribuir para a construção de novos produtos turísticos alternativos e diferenciadores, tendo em conta os fatores intensificadores da experiência turística no âmbito intrapessoal (impactos emocionais, sentimentos turísticos). A emergência do turismo induzido pela produção de séries televisivas, fragmentado pela construção das identidades dos atores, sustentado em argumentos, modos de vida, linguagem, verossimilhança social, área geográfica, país ou cidade, fez emergir uma classe de novos turistas, que se querem distanciar 
do turismo de massas, procuram novos lugares, experiências criativas, diferenciação, férias ativas e novas sensações.

A par deste novo turista florescem um pouco por todo o mundo parques temáticos que constroem imaginários turísticos com base em experiências metamorfoseadas, como encarnar personagens de séries, mudar de forma, figurar-se, alterar a sua natureza e caráter, viver outra época, radicalizar-se em intensificadores alternativos da experiência turística. Estes indicadores podem servir a indústria do turismo na busca de destinos alternativos. Com este propósito, e tendo em conta que os destinos procuram manter-se competitivos perante a forte concorrência, abordar o turismo audiovisual como uma nova tipologia turística a destacar-se dos demais é contribuir para fomentar os novos paradigmas turísticos. Tratando-se de um turismo atual, pode gerar novas dinâmicas e servir stakeholders e redes em torno de novos recursos potenciadores de novos produtos turísticos, suscitáveis de encontrar novos destinos e contribuir para a orientação das motivações do turista na decisão de compra.

\section{Metodologia}

Considerando a escassez de dados para a investigação, dos vários métodos passíveis de utilização, considerou-se que o mais adequado seria a entrevista semiestruturada a especialistas. Tal ocorreu após a definição de várias questões epistemológicas, tendo em conta a natureza do objeto, a produção da série televisiva BORGEN.

$\mathrm{Na}$ fase de coleta de dados secundários, procurou se conhecer a tipologia das séries televisivas com maior audiência. 
Com base no caso da série dinamarquesa BORGEN, identificou-se que os locais de filmagem, as personagens, o tema e argumento e o contexto histórico, são indicadores que influenciam o perfil de audiência. Considerou-se por isso que os objetivos da investigação seguiam na perspetiva de conhecer as condições necessárias de uma produção televisiva de séries para a motivação e indução da visita aos locais de filmagem. Assim, para aprofundar uma das perguntas do estudo no âmbito das motivações de visita aos locais de filmagem, optou-se por encontrar especialistas pela produção audiovisual de Film Comissions, realizando entrevistas semiestruturadas.

Os dados foram recolhidos durante o mês de dezembro de 2017 através do envio de um roteiro de entrevista enviado por email para os respondentes devolverem com as respostas escritas pela mesma via. Atentando-se no quadro abaixo, estabeleceuse uma data limite para a devolução das respostas. No envio do questionário foram esclarecidos os objetivos da investigação e solicitada a devida autorização para a divulgação dos dados. Os contatos do investigador foram também enviados para qualquer esclarecimento ou dúvida que pudessem surgir na interpretação das questões. 
Quadro 1 - Preparação da Entrevista

\begin{tabular}{|c|c|}
\hline $\begin{array}{l}\text { Passos } \\
\text { necessários }\end{array}$ & Descrição \\
\hline $\begin{array}{l}\text { Enquadramento } \\
\text { da entrevista }\end{array}$ & $\begin{array}{l}\text { As entrevistas realizadas pretendem dar resposta } \\
\text { ao objeto geral de estudo: } \\
\text { Contributo da produção de séries televisivas } \\
\text { como fator intensificador da experiência } \\
\text { turística nos locais de filmagem, o caso da série } \\
B O R G E N\end{array}$ \\
\hline $\begin{array}{l}\text { Definição dos } \\
\text { objetivos da } \\
\text { entrevista }\end{array}$ & $\begin{array}{l}\text { Dar resposta às questões de investigação } \\
\text { colocadas: } \\
\text { Q1: Que critérios de seleção estão na base das } \\
\text { escolhas dos locais de filmagem dos produtores } \\
\text { audiovisuais, responsáveis por film comissions, } \\
\text { e como podem estes locais induzir a motivação } \\
\text { para a visita? } \\
\text { Q2: Serão os géneros fílmicos diferenciadores } \\
\text { de públicos e, por conseguinte de turistas que } \\
\text { visitam os locais de filmagens? }\end{array}$ \\
\hline Entrevistados & Responsáveis e/ou produtores audiovisuais \\
\hline Entrevistador & Mestranda em Turismo e Ambiente \\
\hline Prazo de respostas & 15 de dezembro de 2017 \\
\hline $\begin{array}{l}\text { Condições gerais / } \\
\text { contactos }\end{array}$ & $\begin{array}{l}\text { Para qualquer dúvida contactar Ana Paula } \\
\text { Carvalho, } 969841310 \text { ou anapaulasantos. } \\
\text { carvalho@gmail.com }\end{array}$ \\
\hline $\begin{array}{l}\text { Confidencialidade } \\
\text { de dados }\end{array}$ & $\begin{array}{l}\text { Os dados servirão meramente para fins } \\
\text { estatísticos e os nomes dos entrevistados apenas } \\
\text { serão usados para fins académicos. }\end{array}$ \\
\hline
\end{tabular}

Fonte: Autor.

As questões foram formuladas em perguntas-guia abertas, como se apresenta no quadro abaixo, de modo a dar liberdade aos respondentes e consequentes testemunhos e interpretações. 
Obteve-se três entrevistas auto preenchidas, realizadas individualmente e sem interferência do investigador, evitou-se a resistência por conveniência e influência empresarial, bem como, o enviesamento das respostas que se apresentam em Apêndice.

Quadro 2 - Relação entre perguntas e fatores de avaliação

\begin{tabular}{|l|l|}
\hline \multicolumn{1}{|c|}{ Perguntas guia Abertas } & \multicolumn{1}{c|}{ Fatores de avaliação } \\
\hline $\begin{array}{l}\text { 1. Que critérios estão na base da } \\
\text { escolha dos locais de filmagem? }\end{array}$ & a. Locais de filmagem \\
\hline $\begin{array}{l}\text { 2. Que ações e/ou intervenções são } \\
\text { necessárias na preparação de um filme } \\
\text { local? }\end{array}$ & b. Produção de filmes \\
\hline $\begin{array}{l}\text { 3. Que relação estabelece entre uma } \\
\text { produção audiovisual e um potencial } \\
\text { destino turístico? }\end{array}$ & $\begin{array}{l}\text { c. Relação entre produção } \\
\text { audiovisual e destino } \\
\text { turístico }\end{array}$ \\
\hline $\begin{array}{l}\text { 4. Em sua opinião em que medida } \\
\text { é que as séries televisivas podem } \\
\text { influenciar a experiência turística do } \\
\text { destino? }\end{array}$ & $\begin{array}{l}\text { d. Contribuição das séries } \\
\text { televisivas para a experiência } \\
\text { turística }\end{array}$ \\
\hline $\begin{array}{l}\text { 5. Em sua opinião que motivação(ões) } \\
\text { pensa estar na origem da visita aos } \\
\text { locais de filmagem de uma série } \\
\text { televisiva? }\end{array}$ & $\begin{array}{l}\text { e. Motivações para a visita } \\
\text { aos locais de filmagem }\end{array}$ \\
\hline
\end{tabular}

Fonte: Autor.

Para a análise da entrevista, utilizou-se o método de Delphi. Este é um método que consiste na recolha de informação de dados primários através de entrevistas, de modo a facilitar a formação de uma opinião de um determinado grupo de especialistas (HELMER, 1977). A primeira versão da entrevista foi aplicada em pré-teste para verificar a sua adequação e interesse ao estudo. Pretendeu- 
se perceber as dificuldades nas questões formuladas, tendo sido reformuladas à posteriori algumas questões que se adequavam melhor aos entrevistados e aos tópicos a avaliar. A entrevista foi construída com base na revisão da literatura, em trabalhos de opinião jornalística de âmbito televisivo, na consulta dos níveis de audiência e nalguns relatos de espetadores sobre as experiências afetivas na audiência da série, recolhidos através da rede social Facebook e blogues pessoais que contribuíram para fundamentar as principais reflexões.

$\mathrm{Na}$ validação das respostas às questões das entrevistas, foram recolhidas as principais ideias que se encontram expressas no quadro 3. Foram agrupadas em contexto de análise de conteúdo por entrevistado de modo a identificar convergências e divergências nas respostas. Por fim, foi recolhida informação via digital (WebNet) de blogueiros que identificavam relações com a série e com a visita aos locais de filmagem.

Para o objetivo geral do estudo, foram fundamentais as respostas dos entrevistados que ajudaram a compreender melhor os critérios que são definidos nas escolhas dos locais de filmagem. No entanto, é considerado a validade e confiabilidade do método. Segundo Quivy e Campenhoudt (2003), a flexibilidade do método torna importante a capacidade e competência do investigador. Neste caso, a análise do instrumento utilizado pelo Método de Delphi é considerada por alguns autores como uma técnica de último recurso. São apontados vários problemas, entre os quais, a pobre consistência interna e confiabilidade das opiniões entre os especialistas e, por isso, a baixa reprodutibilidade das previsões baseadas nos resultados obtidos, a sensibilidade dos resultados 
em relação à ambiguidade e reatividade dos inquiridos nos questionários usados para a recolha de informação; dificuldade em avaliar o grau de conhecimento possuído pelos especialistas participantes (MAKRIDAKIS; WHEELWRIGHT; HYNDMAN, 1998). Tendo em conta a limitação dos resultados encontrados, parece-nos oportuno voltar ao trabalho, partindo da reflexão inicial, destacando modelos baseados nos constructos audiovisuais e na perceção, promoção e ligação aos destinos turísticos e à relação destes com as experiências diferenciadoras.

\section{Resultados}

Para análise de conteúdo das entrevistas sob a técnica Delphi na identificação dos fatores em estudo, segundo Klaus Krippendorff (1980), a análise de conteúdo é uma técnica de investigação que permite fazer inferências válidas e replicáveis, dos dados para o seu contexto. Tendo sido as entrevistas produzidas individualmente e sem interferência do investigador, a três especialistas, permitiu uma avaliação profunda, exaustiva e comparativa. É de referir que se evitou a generalização analítica e tentou-se que a análise comparativa fosse o mais rigorosa e especifica possível e das principais ideias retirámos as que melhor emolduram os fatores em estudo. Como referido anteriormente, a presente pesquisa qualitativa apresenta alguma subjetividade na medida em que é difícil compreender a experiência, os pontos de vista e os conhecimentos dos entrevistados. Também o facto de o investigador tem falado telefonicamente com dois dos entrevistados pode suscitar deferências na análise. 


\section{Quadro 3 - Análise das entrevistas}

\begin{tabular}{|c|c|c|c|}
\hline \multirow{2}{*}{$\begin{array}{l}\text { FATORES DE } \\
\text { AVALIAÇÃO }\end{array}$} & \multicolumn{3}{|c|}{$\begin{array}{l}\text { ENTREVISTADOS } \\
\text { Principais evidências nas respostas aos fatores de avaliação }\end{array}$} \\
\hline & 1 - Bruno Manique & & 3- João Ferreira \\
\hline $\begin{array}{l}\text { a. Locais de } \\
\text { filmagem }\end{array}$ & $\begin{array}{l}>\mathrm{N}^{\circ} \text { de horas de sol, } \\
\text { Clima, acessibilidades, } \\
\text { segurança, cuidados } \\
\text { ambientais, serviços } \\
\text { de apoio à produção, } \\
\text { benefícios fiscais. }\end{array}$ & $\begin{array}{l}>\mathrm{N}^{\mathrm{o}} \text { de horas de sol, } \\
\text { Tipologia do filme, } \\
\text { ambiente, serviços } \\
\text { de apoio à produção, } \\
\text { benefícios fiscais. }\end{array}$ & $\begin{array}{l}\text { Cenário, apoio logístico, } \\
\text { custos de produção. }\end{array}$ \\
\hline $\begin{array}{l}\text { b. Produção de } \\
\text { filmes }\end{array}$ & $\begin{array}{l}\text { Autorizações e licenças, } \\
\text { qualidade da luz, } \\
\text { segurança, logística } \\
\text { e serviços de apoio, } \\
\text { cuidados ambientais, } \\
\text { montagem de cenários. }\end{array}$ & $\begin{array}{l}\text { Obtenção de } \\
\text { licenças, adjudicação } \\
\text { e contratação de } \\
\text { serviços. }\end{array}$ & $\begin{array}{l}\text { Levantamento } \\
\text { das necessidades, } \\
\text { dificuldades e } \\
\text { facilidades, privilegia } \\
\text { fatores como, luz solar, } \\
\text { condições lumíneas e } \\
\text { cromáticas, ângulos de } \\
\text { filmagem, som, locais } \\
\text { perto com serviços } \\
\text { de apoio (hotel, } \\
\text { restaurante). }\end{array}$ \\
\hline $\begin{array}{l}\text { c. Relação } \\
\text { entre produção } \\
\text { audiovisual e } \\
\text { destino turístico }\end{array}$ & $\begin{array}{l}\text { Concreta e efetiva, relação } \\
\text { causa efeito muito real, } \\
\text { de acordo com um estudo } \\
\text { da AFCI-Association } \\
\text { of Film Commissioners } \\
\text { Internacional, } 1 \text { em } \\
\text { cada } 5 \text { turistas em todo } \\
\text { o mundo é motivado por } \\
\text { filmes ou séries de TV, que } \\
\text { tenham visto. }\end{array}$ & $\begin{array}{l}\text { Notoriedade do } \\
\text { filme, promoção, } \\
\text { os espetadores, } \\
\text { vinculação } \\
\text { emocional à } \\
\text { imagens. }\end{array}$ & $\begin{array}{l}\text { Todos os locais } \\
\text { de filmagem são } \\
\text { potencialmente } \\
\text { destinos turísticos, } \\
\text { "existem cerca de } 40 \\
\text { milhões de turistas } \\
\text { cinematográficos, por } \\
\text { ano, em todo o mundo, } \\
\text { ou seja, pessoas que } \\
\text { viajam em busca de } \\
\text { locais e destinos que } \\
\text { serviram de cenários } \\
\text { para esses mesmos } \\
\text { filmes e séries." }\end{array}$ \\
\hline $\begin{array}{l}\text { d. Contribuição das } \\
\text { séries televisivas } \\
\text { para a experiência } \\
\text { turística }\end{array}$ & $\begin{array}{l}\text { Todos influenciam } \\
\text { independentemente de } \\
\text { séries ou filmes. }\end{array}$ & $\begin{array}{l}\text { Proporcional ao } \\
\text { seu mediatismo } \\
\text { e sucesso, "eu e } \\
\text { um grupo de } 18 \\
\text { amigos decidimos } \\
\text { visitar a Fazenda } \\
\text { das Marrecas, } \\
\text { em Pernambuco, } \\
\text { Brasil, influenciados } \\
\text { pelo facto de lá } \\
\text { se ter filmado a } \\
\text { telenovela "A } \\
\text { Indomada" (da Rede } \\
\text { Globo)." }\end{array}$ & $\begin{array}{l}\text { Existência de Guias, } \\
\text { percursos definidos, } \\
\text { reproduções dos } \\
\text { cenários nos locais } \\
\text { de visita, "para que } \\
\text { os viajantes possam } \\
\text { ali reconhecer as } \\
\text { séries que assistiram } \\
\text { no conforto das suas } \\
\text { casas." }\end{array}$ \\
\hline $\begin{array}{l}\text { e. Motivação para } \\
\text { a visita aos locais } \\
\text { de filmagem }\end{array}$ & $\begin{array}{l}\text { A beleza e o interesse dos } \\
\text { locais, paisagem, cultura, } \\
\text { história e arquitetura todas } \\
\text { relacionadas com a série. } \\
\text { A emoção produzida } \\
\text { ligada à série e aos atores. }\end{array}$ & $\begin{array}{l}\text { Os atributos dos } \\
\text { atores (lugares } \\
\text { de veneração), } \\
\text { dimensão simbólica. }\end{array}$ & $\begin{array}{l}\text { Estar mais próximo } \\
\text { dos seus heróis, } \\
\text { das personagens, } \\
\text { identificação com os } \\
\text { atores. }\end{array}$ \\
\hline
\end{tabular}

Fonte: Autor. 
Com base na análise das entrevistas e na preposição de dar resposta às questões iniciais retirámos as seguintes conclusões tendo em conta as perguntas iniciais formuladas:

\section{Quadro 4-Conclusões às perguntas de partida}

Q1: Que critérios de seleção estão na base das escolhas dos locais de filmagem dos produtores audiovisuais, responsáveis por film comissions, e como podem estes locais induzir a motivação para a visita?

Foi unânime que os locais de filmagem são motivadores e indutores de visita. Ainda assim a referência à notoriedade do filme prevaleça sobre os seus atores. Para a escolha dos locais os fatores evidentes são as questões que se prendem com a logística, os serviços de apoio e segurança, os benefícios económicos e os custos de produção, estes fatores não podem pôr em causa, a qualidade da luz e do som, o ambiente e envolvente, o clima e o número de horas disponíveis para gravação.

Q2: Serão os géneros fílmicos diferenciadores de públicos e, por conseguinte de turistas que visitam os locais de filmagens?

A resposta a esta questão não é evidente, contudo há tendencialmente a motivação a visitar os locais de filme, independentemente do tipo de público ou de filme. Qualquer turista audiovisual se identifica mais ou menos com alguma personagem, história, local ou outro fator.

Fonte: Autor.

\section{Conclusão}

Se por um lado, os locais de filmagem induzem a motivação para a visita e para a construção de novas identidades e de novos turistas que procuram novas experiências, por outro lado, na atual realidade do crescimento (in)sustentável do turismo em determinados destinos, a produção de séries televisivas pode 
ter um papel determinante na diferenciação do perfil de audiência, orientando comportamentos e lógicas agregadoras que podem assim contribuir para a construção de novos destinos turísticos, alternativos e diferenciadores. Esta segmentação de audiência em função de uma determinada série pode ainda ser utilizada em estudos que determinem a influência turística de um determinado destino e a sua contribuição de reparação a partir da indução encenada. Vinculando o que fora apresentado anteriormente, se as produções de séries televisivas levam a uma intenção de visita aos locais de filmagem, estas podem também contribuir para a intensificação da experiência turística e simultaneamente, tendo em conta, argumentos, personagens e temas, orientar comportamentos.

Assim, os objetivos propostos podem ser resumidos em dois momentos. No primeiro, a identificação dos elementos concetuais da experiência turística e dos locais de filme, as motivações e o comportamento do turista audiovisual. No segundo, a metodologia utilizada permitiu obter resultados e conclusões que contribuem para novos conhecimentos relativos à análise do turismo induzido por séries televisivas. Do resultado da presente investigação, acredita-se que pode servir gestores turísticos de destinos e complementar estudos já existentes. Sabe-se que a escolha dos locais de filmagem não é inocente, a sua preparação é cuidadosamente pensada em quem vê, como vê e o que vê, o que suscita a intenção de agradabilidade dos locais retratados. Tal fato pode conduzir os espetadores a elevarem o interesse e admiração pelos locais de filmagens cuidadosamente trabalhados por imagens sedutoras. Por outro lado, estes locais, muito beneficiam com as equipas de produção. Os serviços necessários à produção suscitam 
nos locais impactos económicos, sociais e culturais, designadamente, a contratação de pessoas, serviços de hotel, de restauração, aluguer de viaturas e muitos outros.

Os complexos resultados dos fluxos turísticos e a imprevisibilidade da motivação nos comportamentos do destino, associados ao turismo audiovisual, será outra questão que merece melhor aprofundamento. Será interessante estudar a previsibilidade do impacto da produção audiovisual no turismo, ter estimativas estatísticas dos impactos micro e macro económicos do turismo induzido pelos audiovisuais, e, encontrar potenciais efeitos estruturais nos locais de destino, promovidos pelas film comission.

Uma das limitações foi o tamanho da amostra e a técnica utilizada, pois reduz a eficácia dos resultados obtidos. O fato dos entrevistados serem todos de nacionalidade portuguesa não nos permite extrapolar o estudo. Outra grande limitação é a inexistência de estudos empíricos acerca do tema e do perfil do turista audiovisual.

Apesar de se encontrar alguns estudos na literatura, existem algumas questões que são aqui propostas para serem estudadas e aprofundadas e que podem contribuir para a emancipação dos destinos turísticos.

Uma delas é a correlação de motivação de visita aos locais de filmagem de séries e de filmes de cinema. Qual produz maior motivação de visita, e, nessa visita quais os interesses dos turistas? Tendo em conta a limitação dos resultados encontrados parece oportuno voltar ao trabalho, partindo da reflexão inicial, ou seja, que modelos futuros serão vistos nos constructos audiovisuais e na perceção, promoção e ligação aos destinos turísticos e à relação destes com as experiências diferenciadoras? 
Quais são os resultados dos fluxos turísticos e a imprevisibilidade da motivação nos comportamentos do destino associados ao turismo audiovisual? A ligação deste trabalho ao estado atual da investigação para o interesse sobre a matéria pode conduzir-nos a caminhos entrilhados entre a transgressão e a desejada novidade de resultados obtidos a partir de estudos menos abstratos. Contudo, este primeiro ensaio serviu de orientação a pistas para mais investigações sobre a matéria.

\section{Referências}

ALMEIDA, António Sérgio Araújo. Comunidades turísticas e actores intermediários: a experiência como contributo para a sustentabilidade. In: INTERVENÇÃO ASSOCIAÇÃO PARA A PROMOÇÃO E DIVULGAÇÃO CULTURAL. Teatro e intervenção social. Chaves, 2012. p. 97-110.

AUGÉ, Marc. Pour une anthropologie des mondes contemporains. Paris, Aubier, 1994.

BUSBY, Graham; KLUG, Julia. Movie-induced tourism: the challenge of measurement and other issues. Journal of Vacation Marketing, [S. l], v. 7, n. 4, p. 316-332, 2001.

COHEN, J. Promotion of overseas tourism through media fiction. In: JOSEPH, W.B.; MOUTINHO, L.; VERNON, I. R. (ed.). Tourism services marketing practice. Coral Gables, Florida: Academy of Marketing Science; Universidade de Miami, 1986. p. 229-237. (Special conference series, v. II).

DANN, Graham M. Anomie, ego-enhancement and tourism. Annals of Tourism Research, New York, n. 4, p. 184-194, 1977. 
DIMOSKA, Tatjana; TRIMCEV, Boris. Competitiveness strategies for supporting economic development of the touristic destination. Procedia - Social and Behavioral Sciences, [S. l], n. 44, p. 279-288, 2012.

FU, Hui, YE, Ben Haobin, XIANG, Junzhi. Reality TV, audience travel intentions, and destination image. Tourism Management, Guildford, v. 55, p. 37-48, Aug 2016.

HAYATA, Kivea Sarmento; Madril, Marilia Leticia. Turismo cinematográfico: um novo segmento para o desenvolvimento turístico. 2009. Trabalho de Conclusão de Curso (Graduação em Turismo) - Faculdade Cásper Líbero. São Paulo.

HELMER, Olaf. Problems in futures research: delphi and causal cross-impact analysis. Futures, v. 9, n. 1, p. 17-31, Feb. 1977.

HUDSON, Simon; RITCHIE, Brent. Promoting destinations via film tourism: an empirical identification of supporting marketing initiatives. Journal of Travel Research, Thousand Oaks, Calif., v. 44, p. 387-396, May 2006.

KIM, Samuel Seongseop et al. The effects of Korean pop culture on Hong Kong residents' perceptions of Korea as a potential tourist destination. Journal of Travel \& Tourism Marketing, London, v. 24, n. 2-3, p. 163-183, 2008.

KIM, Samuel Seongseop; ASSAKER Guy. An empirical examination of the antecedents of film tourism experience: a structural model approach. Journal of Travel \& Tourism Marketing, London, v. 31, n. 2, p. 251-268, 2014. Doi: $10.1080 / 10548408.2014 .873316$

KRIPPENDORFF, Klaus. Validity in content analysis. In: MOCHMANN, E. (ed.). Computerstrategien $f \tilde{A}^{1} / 4 r$ die kommunikationsanalyse. Frankfurt, Germany: Campus, 1980. p. 
69-112.

LARA, Raquel Martin. El fenómeno del turismo cinematográfico. 2013. Trabajo fin de grado (Graduado en Turismo) - Faculdad de Turismo, Universidad de Málaga, Málaga.

LI, Shina et al. The economic impact of on-screen tourism: the case of the lord of the rings and the hobbit. Tourism Management, Guildford, v. 60, p. 177-187, June 2017.

MACCANNELL, Dean. The tourist: a new theory of the leisure class. New York: Schocken Books, 1976.

MACIEL, Juliana Pereira. Turismo e audiovisual: influências das telenovelas no turismo. 2015. Tese (Doutorado em Turismo) - Faculdade de Turismo e Hotelaria, Universidade Federal Fluminense, Niteroi.

MAKRIDAKIS, Spyros; WHEELWRIGHT, Steven C.; HYNDMAN, Rob J. Forecasting: methods and applications. $3^{\text {rd }}$ ed. Lancaster: John Wiley and Sons. Resenha de: Alvaro E Faria Jr. International Journal of Forecasting, Amsterdam, v. 18, p. 158-159, Jan./Mar. 2002.

NIELSEN, Christian. Turismo e mídia: o papel da comunicação na atividade turística. São paulo: Contexto, 2002.

NUNES, Sara A. Los destinos turísticos en las producciones de cine y televisión. Influencia en su notoriedade e imagen de marca y en la elección del consumidor. 2016. Tesis (Doctoral) Universidad de Extremadura, España.

OLIVEIRA, Frederico Ferreira. Comportamento do consumidor: um estudo das teorias de marketing aplicadas ao turismo. 2008. Disponível em: http://pro-thor.com/wp-content/uploads/artigo5-comportamento-do-consumidor-um-estudo-das-teorias-de- 
marketing-aplicadas-ao-turismo.pdf. Acesso em: 10 nov. 2017.

PLOG, Stanley C. Where in the World are people going and why do they want to go there? In: TIANGUIS TURÍSTICO, 1979, Mexico City, México. Paper [...].Mexico City, México, 1979.

QUIVY, Raymond; CAMPENHOUDT, Luc Van. Manual de investigação em ciências sociais. Lisboa: Gradiva, 2003. Carlton S.VanDoren3

RILEY, Roger; BAKER, Dwayne; DOREN. C.V. Movie induced tourism. Annals of Tourism Research, New York, v. 25, n. 4, p. 919-935, 1998.

WANG, Ning. Rethinking authenticity in tourism experience. Annals of Tourism Research, New York, v. 26, n. 2, p 349-370, 1999.

WINNICOTT, Donald. O brincar e a realidade. Rio de Janeiro: Imago, 1971.

YOUNG, Anita Fernandez; YOUNG, Robert. Measuring the effects of film and television on tourism to screen locations: A theoretical and empirical perspective. Journal of Travel \& Tourism Marketing, London, v. 24, n. 2-3, p. 195-211, 2008. 